\title{
Analysis as assemblage: Making sense of polysemous texts
}

Accomplishing critical literacy within a mediascape where texts present as polysemous and ambiguous, may be the challenge of our times. This paper uses the example of a seemingly paradoxical newspaper column that contains paratextual elements, to illustrate how an assemblage of critical analytical approaches is needed to make fuller sense. The column is read in three ways, focusing first on the main column, its location, imagined audience, its use of rhetorical devices such as satire, irony, humour and repetition to critique the state of global football. The second reading uses a postcolonial feminist perspective to focus exclusively on the curious supplementary tailpieces (shirttails) that end the column. It reveals how specific translation strategies and the representation of certain bodies as sexually voracious, deviant and excessive, frame them as absurd exotic-erotic objects of a neo-colonial gaze. The third reading leans on Derridean ideas of writing and text to understand the seemingly discrepant relationship between column and shirttails, to raise critical questions about the role of the reader/readership itself. Each analysis brings different sensibilities to the work and illustrates the value of assesmbling multiple analytical approaches to work towards critical media literacy. The conditions and caveats of such working arrangements are also considered.

Keywords: polysemy, paratext, critical literacy; postcolonial feminist analysis; Derridean analysis; assemblage/working arrangement

Contemporary media texts pose a challenge when they present as ambiguous and enigmatic, offering strangely disjointed, multiple, even contradictory meanings. If we take seriously the task of critical literacy as entailing a process of reading words and worlds through 'processes of naming and renaming the world, seeing its patterns, designs and complexities (Mey, 1986), and developing the capacity to rewrite, redesign, and reshape it in communities' interests (New London Group, 1996)' (Luke \& Woods, 2009, p. 9), then learning to analyse and account for the role of media texts in shaping culture and power (Luke 2012) is not straightforward. The media context is increasingly characterised by an implosion of production processes, forms and meanings of works, all of which pose a challenge for pedagogy and analysis that engender critical literacy. It is also not uncommon to find features such as press articles that deviate from their headlines, photographs that are more ambiguous than their titular ambitions (and vice versa), and authors/producers taking contradictory positions within the same outlet/forum. Even in the case of longer established newspapers, where a 'red-top' tabloid or a 'liberal' broadsheet would each be expected to frame the world in predictable ways, speak in a familiar language and send recognisable messages to their respective constituencies (Gentzkow, Shapiro \& Sinkinson, 2014), journalistic pieces present themselves in far more polysemous ways than anticipated. Critical reading becomes more complex when the mediascape is also labrynthine, and outputs are rarely stand-alone items. Works come attached to paratexts - hyperlinks, trailers, promotional materials, spin-off products, even book covers and prefaces - which can "change, edit, revise or outright create meaning" (Brookey \& Gray, 2017, p.101). Such supplementary texts may also be produced through diffused production processes, where authors/producers are multiple and rarely share a central vision across the texts, contributing to a sense of fractured or incoherent stances. To accomplish critical literacy, a reader would need to comprehend and account for their inter-relationships, roles, meanings and audiences. This paper hopes to illustrate how an engagement with these polysemous and shape-shifting features of contemporary media texts that does not ignore their complexities and contradictions, requires critical reading practices that work with more than one dominant perspective. The paper came into being partly as a response to a pedagogical challenge, as it was far easier to find (and teach with) examples of single perspective analysis of texts, than consciously curated and assembled, multiple perspective analyses that allowed varied, divergent readings that deepened critical engagement. The argument advanced here is that an assemblage, or a 'working arrangement' 
(Buchanan 2015) of analytical approaches may be needed to illuminate and articulate features of contemporary media texts that may escape the scrutiny of a single approach.

The text chosen for analysis in this paper is the sports column 'Said and Done', which appears in The Observer, a British Sunday paper with the reputation of being one of the most politically 'liberal' weeklies. The column is chosen for its supplementary tailpiece - a 'shirttail' - in journalistic parlance. Shirttails are similar in nature to postscripts or appendices. They are succinct and supplementary; related, yet distinctive from the preceding material and bear a curious relationship to the 'main' text. The shirttails of this column are distinct from the main column in terms of content, and act in a paratextual capacity, rendering the text ambiguous, revealing its polysemous, even contradictory impulses. The column is compiled by football (soccer) writer David Hills, a Sports Journalism Awards winner, and usually appears on pages 8 or 9 within the Sports section of The Observer. It is also available on the internet, on its sister newspaper, The Guardian's web pages:

https://www.theguardian.com/football/series/saidanddone.

FIGURE 1: Page shot of column from March 12, 2017 (INSERT PAGE SHOT HERE)

As longtime readers of the 'Said and Done' column, we have collected and examined approximately 200 editions in which the shirttails featured, from 2008 to 2017. The column itself does not appear every weekend, but loosely follows the English football league season from the middle of August to the end of May. The shirttails feature in approximately 20-25 editions of the paper each year. To make the argument for the necessity of an assemblage of readings, the paper is presented in three sections, the first of which focuses on the main column, its content, style, rhetorical devices and imagined audience, to offer a commentary on how/why it works. The second section focuses exclusively on the shirttails, using a critical postcolonial feminist perspective, and the third section offers a critical Derridean reading, looking across both the main column and the shirttail. Each analysis brings with it, slightly different insights and impulses to the task of critical reading.

\section{Reading the main column}

The column is best described as a compilation of tightly crafted snippets of information on a range of football related issues. It focuses largely on corruption within FIFA (Federation Internationale de Football Association), financial mismanagement/fraud, hypocrisy and double speak, and on behaviour related to racism, sexism, homophobia or anti-Semitism within the game. It takes aim at a range of people associated with football - players, officials, managers, fans and clubs. Some snippets below illustrate the style and content of the column -

\section{Greed update}

Michel Platini says football greed could result in "financial implosion". Clubs "must not delude themselves that the growth of income in football is an endless upward spiral" and should show corporate and social responsibility. Uefa's lead: £220m - final Uefa profit from Euro 2008, a new record, thanks to social-responsibility rich, obesityhating corporate family Coca-Cola, Carlsberg and McDonalds. (Feb 22, 2009)

\section{Swings and roundabouts}

22m: Number of South Africans who live on less than $£ 2$ per day.

$£ 1.7 \mathrm{bn}$ : Current forecast for Fifa's overall profit from the World Cup, with all income from broadcasting, marketing and tickets channelled out of South Africa. 0: Amount of tax that Fifa - a Swiss-registered charity - will pay on the £1.7bn. (June 13, 2010) 
£85m: Premier League clubs' spending on transfers in 24 hours last week - £835m in three months. $£ 85 m$ : The FA's spending on grassroots football over four years, via the last Sport England funding cycle. (Sept 6, 2014)

The snippets are always presented minimally, in pithy sentences, without any overt commentary. Yet the crafting of the phrases and the juxtapositioning of information, send an unmistakable message of critique directed at the capitalism-media-sport nexus (Boyle \& Haynes 2009) that characterises the game. To do this, the column relies on sensibilities associated with satire, which typically aims to demonstrate and expose 'human vices or follies in order to scorn or ridicule humans' (Streicher, 1967, p.431). Satire and caricature, its pictorial version, both depend on varieties of humour to ridicule/lampoon a subject by drawing attention to its flaws (Beckson \& Ganz, 1989). Satire therefore involves a implicit critical commentary on the world (Kreuz \& Roberts, 1993). While satire is directed at the state of affairs or a section of society, its relation sarcasm, is usually directed an an individual. For instance, in the snippet presented below, sarcasm is used to expose the folly of awarding an anti-homophobia awarded to a known homophobe.

\section{Fastest turnaround}

Montpellier owner Louis "Loulou" Nicollin. March: Given an anti-homophobia award for renouncing his own mixed record, which included a ban for calling a rival "a little poof" in 2009; April: Award withdrawn after an on-air relapse - Loulou explaining why he had stayed away from a match: "It was just too stressful for me. Yes, I know, I'm a fag." (May 12, 2012)

By exposing homophobia and naming and mocking homophobes at top levels of the game, the column offers a critical commentary and signals its stance, also possibly enlisting readers to its position.

Another rhetorical device used to good effect is that of repetition. Certain 'protagonists' are featured consistently, over many years, allowing a regular reader to follow what is usually an abysmal track record of behaviour. In the following snippet, Italian FA head Carlo Tavecchio is in the spotlight but other prominent FA heads such as Sepp Blatter and Jack Warner are all frequent targets.

Also last week: reactions in Italy to Uefa banning Tavecchio from its committee meetings for six months after he called black players "banana eaters".

Tavecchio: "It makes no practical difference to me. I won't miss out on anything." Serie B president Andrea Abodi: "It's not a real ban, is it? Frankly, I'm more and more convinced that Tavecchio was the right choice as president." (Oct 11, 2014)

Carlo Tavecchio: reflecting on his record after a "media witch-hunt" forced him out as Italy's FA president: "Two hundred and forty people work for me here. Two hundred and forty people are in tears. "His take-away message for the press, a week after Italy's World Cup exit: papers should "publish all my achievements in football", not keep listing his missteps. Tavecchio said talk of his four financial crime convictions, his sixmonth racism ban, his leaked comments about "lousy Jews" and "keeping gays away from me"; his reference to female players as "handicapped"; his call for clubs to host lap dancing venues; and new claims he sexually harassed a female executive, telling her "come here and let me touch your breasts", which he denies, distracts from his "record of success ... All [the press] ever wanted was Tavecchio on the cross." (Nov $26,2017)$

Here, the reader is expected to note the irony highlighted by the discrepancy between the Tavecchio's record and Tavecchio's statements. Both satire and irony are devices that rely on this gap between the representation and the states of affairs (Kreuze \& Roberts, 1993) and both 
are similar in their open-endedness, in that they do not spell out every nuance and detail. Scholarship on political satire in the media suggests that this may result in irony that may not always being read as intended, and that consumers of media may often see what they what to see (LaMarre, Landreville \& Beam, 2009) and that people cannot be counted on to laugh at the 'right' things (Colletta, 2009, p.864). Thus satire and irony are not very effective political strategies even as they may be hopeful in spirit (Colletta, 2009). All of this suggests that the column's practice of combining brevity of expression with satire and irony ought to leave plenty of room for ambiguity of meaning. However, in spite of its reliance on rhetorical devices that facilitate multiple meanings, we propose that the column still manages to convey its politics, intent and meaning rather clearly. A closer look at the location and assumed reader dispositions may explain how such meaning is firmly secured.

The column, as is true of all texts, is framed by reader expectations and anticipations that play an important role in text comprehension (Gibbs, Kushner \& Mills, 1991; Zwann, 1991). The particular section of the newspaper - Observer Sport - positioned itself thus: "Observer Sport aims to provide the reader with unrivalled reporting and analysis of both domestic and global events - and to pepper the pages with a sense of fun. The Observer is a campaigning paper, having led the way in the debate about the state of football..." (Archived material from April $30,2010)$. Through a distinctive combination of its location, its vexed/trenchant tone, and fuelled by the purpose of exposé, this particular column mocks the state of global football and manages to provide that 'sense of fun' while railing against the state of football. In consistently exposing malpractice, poor governance and politically unacceptable behaviour, the column manages to match the conventional expectations of a 'liberal broadsheet' in the UK context. In addition, the Observer-Guardian publishing house notes, "The Guardian attracts a unique group of people. People curious about the world around them... Progressive people, valuable people." https://advertising.theguardian.com/audience. The column therefore assumes, and encourages a readership that can see itself as 'progressive', with a politically liberal bent, someone who is an informed and engaged reader, with wider interests/concerns about society that extend beyond football itself. The column's cryptic style certainly expects such progressives to be active readers willing to 'join the dots', anticipate the message and 'fill in' for when a snippet may, on its own, be too cryptic. However, what jars with this self-styled liberal approach to readership are the shirttails, the final (or penultimate) snippet of the column whose content revolves around the scandalous, romantic or sexual lives of footballers and their model or actress girlfriends/lovers/wives. In the following section, we analyse the ways in which the shirttails depart from the main column and stage an 'exotic-erotic Other'.

\section{Reading the shirttails}

One of the striking features of the shirttails that caught our attention as feminist readers, was the salacious, gossip-magazine style content focusing on female partners of predominantly Latino footballers that stood out in contrast to the rest of the column's preoccupation with loftier issues related to governance of the game. The shirttails seemed to be an after-thought, a 'light-hearted' item on which to end the column. They are usually preceded by the subtitles "Plus:" or, "And finally:" which also signal their status as linked and yet distinct from the rest of the column. Most subtitles also specify the nationality/country related to the incident, usually Brazil, Peru, Argentina, Paraguay, Ecuador, Mexico and other 'Latin' American countries. Together, they set up the curious web of entertainment connecting football, nationality, gender and sex. Such seeming distinctions from the main column position them as a supplement, a paratext.

The focus of the shirttails on Latino nations, gender and sex lends itself to a critical postcolonial feminist reading. Feminist and anti-colonial readings share common ground in their challenge of dominant ideas of culture and representation (Loomba, 1998), and the unfortunate by-product of colonialism - hypermasculinity (Prasad, 1997). They prioritise an analysis of cultural forms and social relations with the aim of challenging unequal power relations within and between 
genders, societies, nations/cultures (Prasad, 2003; Moore-Gilbert, 1997; Flax, 1990). Reading the shirttails through this lens revealed that in addition to the devices displayed in the main column - brevity, irony, satire and repetition - exoticising techniques of translation and an eroticising representation of bodies as wild/untamed were particular to the shirttails. Such representations combine to produce Othering effects and raise questions about the politics and message of the shirttails which seems to contradict the clarity of intent of the main column.

\title{
Repetition and humour in the shirttails
}

As in the main column, the shirttails choose to report on certain characters over a prolonged period, except that they were usually female and only loosely related to the world of football.The case of Larissa Riquelme, a glamour model from Paraguay who dominates the shirttails over several years (2010-2017) illustrates this point:

\section{And finally}

New last week from model Larissa Riquelme: says her brother Freddy is "unhappy" after being arrested in connection with \$200,000 bank robbery in Paraguay. Police acted after Freddy uploaded photos of himself holding large piles of cash to Facebook. Larissa: "Freddy, the world is against you - but I love you little brother." (Nov 7, 2010)

\begin{abstract}
And finally
New last week for football model Larissa Riquelme: beating Justin Beiber as Peru's most Googled celebrity, but left distressed after brother Freddy was sentenced to 5 years' house arrest for adding zeroes to a cheque and trying to cash it. (Dec 12, 2010)
\end{abstract}

Paraguay: Football model Larissa Riquelme launching her 2014 World Cup product
range, including Brazil-themed adult toys and a signature perfume, Revalacion by
Larissa. "We've made 1,000 bottles ... God has a great purpose for my life." (April 26,
2014)

Paraguay: 2010 World Cup model Larissa Riquelme, upset by rival interest in her partner, Cerro Porteño midfielder Jonathan Fabbro: "Everyone says footballers are base, but really it's the models who are dreadful. What do I say to them? One word: karma. I tell them they will pay." (April 24, 2016)

Ecuador: Serie A El Nacional, offering fans the chance to pay $\$ 100$ for dinner with new official club model Larissa Riquelme as part of an "engagement strategy". Riquelme: "I'm very happy. I will sign autographs and encourage new members. It's a passion of mine." (Aug 20, 2017)

Embedding such continuity within the shirttails allows readers to follow the colourful lifestyles of these protagonists, through their ups and downs, reminiscent of Latin telenovelas that are expected to feature improbable and convoluted plots connecting celebrity, sleaze, sex and football. The humour of the shirttails still relies on sarcasm, but it is closer to what may be considered 'traditional' British humour, involving innuendo (of a salty, seaside variety), farce, a sending-up of authority or institutions, and caricatured bodies with prominent breasts and/or bottoms popularised in quintessentially British products like the Carry On films or the Monty Python series (Leach, 2004). The shirttails retain many of these bawdy yet critical features.

\section{Plus: Bad Week For}

Cibelle Ribeiro - former alleged partner of Brazilian congressman Romario reacting to her defeat in the final of Brazil's Miss Bumbum 2012. Ribeiro, who survived an early pageant disqualification when X-rays cleared her of having implants, told the press: "There are some hug assess out there." (Dec 2, 2012) 


\begin{abstract}
Plus: love news
Brazil: Model Amanda Pinheiro on the enduring need for class. "Many Wags desire fame, they take advantage and show off in the press, go out with anyone, and that's up to them. I'm just more discerning. I do take delight in players' bottoms - but I do nothing to lead them on."(01/11/2014)
\end{abstract}

The work of irony in these shirttails also feels different from that of the main column, and worthy of a closer look. Ironic humour, as mentioned previously, is ambiguous and cannot guarantee that readers will laugh at the 'right' things, that is, things that the author hopes will be laughed at. But what makes it different from the ironic humour of the main column is that they seem to be underpinned by a masculinist/sexist ethos. Feminist work on British men's magazines (Benwell, 2007) has pointed out that it is hard to pin down the meaning or intent of such 'lad' humour : "...the discourse is so exaggeratedly macho it is seen by ... readers, as ludicrous" (p. 546). But they are also seen as "intentionally and strategically ironic (and thus smart)" (p.546), thereby recuperating masculinist values, not destabilising them. Many of the column's shirttails engender a humour that is so ambivalent that it can lend itself to the accommodation of contradictory views and in doing so, nods to a tradition of colonial and sexist humour, sustained by the caricature of geographically and culturally distant Latin footballers and models.

\title{
Translation for Othering
}

The shirttails further signal the 'cultural distance' of the objects of the shirttails through particular techniques of translation. Despite the global nature of English and the legitimacy and credibility of World Englishes (Schneider, 2007), this column achieves the effect of Othering through its choice of words and phrases in translation. For example:

\section{A fine romance}

Peru: Sporting Cristal's Amilton Prado says he has "distressed" himself with his infidelity. "I am thoroughly awful - I distress myself." Prado was caught dating "exuberant" dancer Cindy Merino, who she says is now fed up with media attention. "Stop calling. I'm changing my number. Think what you like about our dalliance: it was a fine romance." (Jan 10, 2010)

\section{Plus: Model news \\ Argentina: Boca's Chrisitian Lucchetti says he's "agitated" by model Narita Rodriguez claiming an affair. "It's terrible reading all her barbarities." Rodriguez said Lucchetti was "deep ...he told me the earth moved." (May 29, 2011)}

Attention to the non-English speaking identity of those involved is provoked through the unusual use of words like 'distress', 'exuberant' and dalliance' in the first quotation, and 'agitated' and 'barbarities' in the second, mostly, accompanied by double quotation marks. They raise questions about the language of the speakers, and how their (presumably) Castillian words had been translated in an excessively vernacular style to signal the identity of the speakers, as Latino/a. It is curious that although many of the protagonists featured in the main column are also non-native speakers of English, the exoticising translations only come into play in the shirttails.

The scholarship on translation reveals that the task of any exoticising translation is to retain the novelty of the subject and their Otherness through references to the 'untranslatability' of their words as a 'rift between cultures' (Cortes, 2003, p. 150; Weiguo, 2013). A trick of colonial translation, the kind that seeks to highlight the incomprehensibility of other language-cultures, is often to create the radical Other "through minute details that stand metonymically for the whole" (Cortes, 2003, p.147). The strange placement/choice of words provides these minute details which 
exaggerate and come to 'stand for' a whole culture. Such othering is clearly the result of a particular translation ethic that emphasises difference and Otherness to produce the effect of the 'exotic'.

This emphasis on the exotic and the 'rift' between cultures then draws to the foreground, the imagined reader. The exoticising techniques of translation would make little sense if they did not also evoke the intended metropolitan audience (Mills \& Sen, 2004) - predominantly white, liberal, European and male. The imagined Observer Sport readership thus silently retains a salience in these portrayals of exotic Latinos.

In addition to exoticising effects, the shirttails also deploy bodies and their actions (in concert with their utterances), to animate the 'erotic' Latin. Football stars and glamour models are both required, in their caricatured forms, to exhibit certain gendered bodily features and affects muscular, licentious men, and hyper-feminine, sexually available, passionate women. The shirttails draw on colonial tropes of the erotic body to articulate this "affective labour", to produce 'immaterial, intangible feelings' (Rivers-Moore, 2013), such as passion and excess and sustain colonial stereotypes of 'Latin sexuality' (Arrizon, 2008).

\title{
Wild, undisciplined excess
}

The bodies in the tailpieces are often presented as out of control and somehow untamed. Framing bodies as deviant, disobedient and undisciplined, and thus as reflecting uncivilised, morally dubious or weak characters (Sen, 2004) is a familiar trope of colonial discourse.

\author{
And finally \\ Flamengo's Adriano says he's leaving on-off girlfriend Joana Machado again after she \\ entered talks over a nude Playboy shoot despite promising to be more modest. \\ Machado, accused last month of attacking Adriano's car with stones, had his name \\ tattooed below her breasts last year. I'm branded! This is utter love (April 18, 2010)
}

In this snippet, the football player, Adriano, is presented as leaving his untameable girlfriend as she cannot abide by his needs for her to be more modest. Machado's wildness is evidenced by her stone-throwing, and in tattooing/branding herself with his name below her breasts, her erotic and passionate nature is displayed. In the following quote, another model is presented defending the honour of her boyfriend in an out of control manner that suggests that she is simultaneously, loyal as a partner, as well as unrestrained.

\author{
Plus: Model News \\ Argentina: Model Cinthia Fernandez says reports she responded to a Huracan fan \\ calling her partner Matias Defederico 'rubbish' by beating him while swearing are \\ overplayed... I only reacted to defend my family. (Oct 28, 2012)
}

Latina models' threats to pose nude or make love in public, exhibiting their disregard for societal norms of traditional femininity are consistently presented in the shirttails.

\section{Plus: protest of the week \\ Argentina: Model Milena Hot says she'll strip on the steps of Argentina FA to protest at refs picking on her local club All Boys... Hot says her methods work. It will not be my first nude protest. I did one a while ago against paedophilia. I'm all about human rights. (Mar 13, 2011)}

This snippet is particularly ambiguous as it sends out multiple messages. Milena Hot may be read as an emancipated woman who is empowered to use her erotic capital, being intentionally playful in linking a famously feminist form of protest to direct attention to a seemingly trivial matter or she may be read as entirely serious and as a worthy object of mockery. The open- 
ended nature of the text does not offer clues about the author's or model's intentions. From a postcolonial feminist perspective, McClintock's analysis of the role of the 'porno-tropics' in European imagination may be more instructive in locating such representations: "For centuries the uncertain continents - Africa, the Americas, Asia - were figured in European lore as libidinously eroticised. Travellers' tales abounded with visions of the monstrous sexuality of far-off lands...", such that these places functioned as a "fantastic magic lantern of the mind on to which Europe projected its forbidden sexual desires and fears" $(1995$, p.22). The shirttails seem to draw on features of this trope, portraying Latinos as the epitome of sexual aberration and excess, put to use in the service of the metropolitan reader.

While the glamour models are presented as wild/untamed and exceeding 'civilised' norms, the Latino footballers themselves have fewer mentions in the shirttails. Where they do appear, it is with reference to their predilections for parties, orgies, fast cars, and lavish living, but also occasionally through instances of overt sexism, physical assault and even murder.

\begin{abstract}
Party News
26 Nov: Corinthians striker Adriano says he dropped model Luana Kisner to focus on losing weight. She's good, but it couldn't carry on. I had a choice: football or parties. I have to devote myself to football. 2 Dec: Misses training with chronic diarrhoea after an all-night Sao Paolo flat-warming session. Kisner: Many models were there! He likes to party! (Dec 4, 2011)
\end{abstract}

\title{
Plus: best impact
}

Argentina: Dani Osvaldo marking week one on loan at Boca Juniors with an alleged hotel fiestita involving four team-mates and two female guests - days after he told the press: I'm here to lend a hand, with humility. I just hope it all goes well. (Mar 1, 2015)

This lifestyle is noted as affecting their football performance on the pitch and presented as the norm for Latino footballers, playing to dominant stereotypes of Latin men as passionate and charismatic lovers, as possessing 'natural' footballing talent but also as lacking in hard work and athletic discipline. The failure to live up to 'civilised' standards is also presented through their articulation of sexist beliefs:

\section{Best New Man}

Deportivo San Martin's Mario Leguizamon, sacked in Peru in April after saying this on TV about female referee Silvia Reyes: Why did she send me off? You should ask the fat whore! In my opinion she'd obviously missed out on getting a good bit of big cock that morning, that's all. I don't know why there are women refs. It's like women's football it's neither feminine nor football. (May 11, 2008)

In the larger context of the column and the newspaper, shirttails such as this can appear as if they are meant to expose the sexism within South American football. However, the reporting is set within a masculinist frame, where the presentation is sensational and censure is implied rather than explicit. The weight of the 'liberal' column and the newspaper allow one to assume that this shirttail is not meant to approve the views of Leguizamon but in its cryptic presentation, is equally open to charges of sexism by omission (Ross \& Carter, 2011). Such ambiguity is a more consistent feature of the shirttails compared to the main column:

\section{New man of the week}

Brazil: Juventus-SC coach Celso Teixeira - denying he called a female official "hot" while being sent off. "I'd never be so dumb, I have no sexism. But I will say this, and it's not prejudice. If she was my daughter she wouldn't be wearing those shorts. Why must they be so tight?" (April 12, 2014) 
While the shirttail apparently mocks the male Latino footballer for his aggressive and misogynist attitude to female referees, the online version of the paper contains a weblink leading to a site providing a photograph of the referee in said shorts, during the game. The strange double takes of the shirttails are evidenced elsewhere too:

\title{
Plus: Saddest Exit
}

Brazil: Brasiliense president Luis Estevao. Last month: celebrates record web traffic after expanding the club's website's online porn output, officials revealing: He chooses all the models himself. (April 8, 2012)

The last phrase is particularly striking in its ambiguity as it is not clear if the club president is being censured or envied within the seemingly all-encompassing 'lad' culture of football.

\section{Hyper feminine, heterosexual norms}

The shirttails also consistently use Latina bodies to signal an exaggerated femininity and sexual availability that point to the dominant sexual and gender norms of the context. For example,

\section{Best model \\ Dallys Ferreira: more confident than ever that Paraguay will reach the final. The players know my pledge still stands. Last month Ferreira revealed she will make love to all footballers if they win. Women from my country are ardent... I take no notice in societal norms (June 13, 2010)}

The insistence of Ferreira in this quote, that she is living up to the ardent Paraguayan stereotype but that she would not adhere to societal, perhaps Catholic norms is but one representation of Latina femininity in the shirttails. In contrast are also presented other versions of hyper femininity which open up when maternity and motherhood arrive.

\begin{abstract}
And finally
Uruguayan supermodel Zaira Nara on her love for Diego Farlan: Diego has given me a time limit to become pregnant. By the time of the 2014 World Cup he wants me to have produced at least once. It is a lovely state of affairs. I am ready for a quiet life. (Sept 26, 2010)
\end{abstract}

\section{Plus: moving on}

Argentina: Playboy model Cinthia Fernández - ex-partner of San Lorenzo's Jonathan Ferrari, Racing's Iván Pillud and self-styled "Queen of Thongs" - says having twins with Huracán's Matias Defederico will change her. "No more nudity. Look, I'm not going to become a nun or anything - but it's time to rein it in." (May 18, 2013)

Analysts of contemporary Latina subjectivity point to an ambiguous, often contradictory nature in which their sexuality and sensuality is talked about (Arrizon, 2008), and these particular snippets position the models as transitioning between the extremes of the Madonna-Whore dichotomy ${ }^{1}$ offered to Latinas. Perhaps unsurprisingly, the most prominent of societal norms that is included in the shirttails is that of heterosexuality. In the following extracts, the female models are portrayed professing their desire for 'real', 'uncouth', 'non-metrosexual' men, as a foil to their own earthy passions, sexuality and hyper-femininity.

\footnotetext{
${ }^{1}$ The Madonna-whore dichotomy refers to the polarized subject positions on offer to women on the one end a seductive, dangerous sexuality which is simultaneously seen as titillating and shameful, and on the other, a virginal and obedient chastity embodied by the Madonna (Marianismo).
} 


\begin{abstract}
Love news
Model Amelia Granata says she's having a tubby man after leaving River Plate striker Christian Fabbiani. I do not want another metrosexual: I seek a proper uncouth man with a gut. And let it be known to such men: I like to be disgusting. (Feb 21, 2010)
\end{abstract}

\title{
Plus: model news: Brazil
}

Nicole Bahls, turning her back on "metrosexual" footballers after leaving defender Victor Ramos. "In general they spend too long talking about diet and makeup and discussing their face creams. It's not for me. I prefer something more uncouth." ( Feb 3, 2013)

In the caricatures of the shirttails, the hyper feminine and the hyper masculine are thus consistently presented as desired and desirable positions, somewhat in contrast to the increasing visibility of 'metrosexuality' in the footballing world (Anderson, 2010; Adams, 2011; Magrath, 2017).

The analysis thus far reveals the shirttails to be a tightly crafted compilation, structured and translated in ways that Other. The shirttails, in the context of the whole column are presumably meant to be read as part of the critique of the state of football and lifestyles surrounding elite football. Yet the presentational style and narrow focus on Latino nationalities, and erotic-exotic bodies, reveals an uncritical undercurrent that places the shirttails at odds with the apparent political critique of the main column. The critique from a postcolonial feminist perspective in contrast, is explicit and offers opportunities to understand the actions and utterances of the actors, not as exotic or bizarre, but as familiar, rational and situated within particular global patriarchal and racist structures. For example, Savigliano (1995) analyses that for peoples exoticized by Eurocentric colonial discourses, passion plays a major role in the production of exoticism, and passion becomes the currency through which exotics negotiate their identity with each other and with exoticizers. And when women are portrayed in the shirttails as using nicknames such as 'strawberry', 'melon' and 'caviar', they are echoing earlier colonial practices when local/indigenous women were represented as consumables, equivalent to fruit or vegetable, and as the reward for male colonizers (McClintock, 1995). Such self-tropicalised, self-exoticised nature of Latina talk becomes intelligible in the context of a colonising, patriarchal gaze that bestows value and capital to hyper-sexuality. Irigaray's observation that in particular social situations women perform femininity as a necessary social mask (1985), an ironic performance that is also a strategy for survival helps makes better sense of the actors in the shirttails.

The notion that the Latin body is a convenient fiction - a historically contingent, mass-produced combination of myth, desire, location, marketing, and political experience - mediated through various forms of visual representations and discourse (Mendible, 2007, p.1) also goes unremarked in the shirttails. Instead, there is "an articulation of difference in racial and sexual forms" (Bhabha, 1994, p.67), reminiscent of its role in the construction of colonial subjects. These creations are also notable for the implicit violence (Weiguo, 2013) in that any change or resistance to such stereotypes can be interpreted as a corruption of the 'pure', thus denying the complexities and differences with that culture's ongoing construction. Such discussion/critique is not available through the shirttails, although they do raise implicit rather than explicit questions about the curious connections between media, models and footballers. But for all its implicit critique, the shirttails present a world where women's football is invisible, the men are largely defined by their sexual practices rather than footballing prowess, and the women primarily appear as sexual objects.

This reading helps explain why the shirttails felt like a strange juxtaposition at the end of a column on a 'campaigning' drive to expose corruption, racism and sexism. However, while this analysis identifies the problems with the shirttails, and informs, exposes and explains the 
discomfort of the critical reader, it does not/cannot explain its paradoxical relationship with the main column or why there is an apparent fissure in the text. In response to this challenge, we turn to Derridean approaches to text and writing to seek ways of making additional, different, and multiple senses of these texts.

\section{Reading with Derrida}

Derrida's approach is unusual in that it does not to look at language just as the carrier of meaning, but more as a structure of marks and sounds which are, of themselves, undecidable, and therefore something upon which meaning is imposed (Derrida, 1976). So rather than primarily read a text for meaning, Derridean practice would insist on paying attention to how writing inevitably becomes a process of imposing meaning on chaos, contradiction and meaninglessness. Derrida's unusual approach to texts can be understood through his wider claim that the world itself is chameleonic, even phantasmic (Cooper, 1989). This requires that knowledge/discourse must be 'constructed', or hewn out of it. In the hewing of the texts therefore, the flux and flow, the ambivalence and the contradictions of the world is inbuilt. In this sense, writing for Derrida, is less about content and meaning (i.e. what is traditionally 'mined' in text analysis or ideology critique) and more about structure and organisation of representation. Writing becomes about 'ordering, listing, display, hierarchy of arrangement, edge and margin, sectioning, spacing, contrasts...' (McArthur, 1986, p.23). Hence a Derridean analysis would focus on the rhetorical tactics, the curatorial nature of writing and the puttogetherness of texts.

This does not mean that the text is not analysed for meaning, but that 'meaning' is but one aspect of the analysis, and that other, different sensibilities to the text need to be accommodated to further open up the text. Derrida himself, as a 'supreme' reader of texts (Critchley, 2005) can often be observed doing this kind of multiple reading - the more obvious rigorous and scholarly reading, paying meticulous attention to the context in which texts are written, the contexts of their (intended) reception, the corpus of the author in its longitudinal range, etc; and yet simultaneously, attempting to prise open the blind spots in the text to reveal its 'vouloir dire', so that the text is brought into contradiction with what it purports to claim. These contradictory impulses take texts both seriously, even respectfully, but also quizzically and inquisitorially. This requires both an attitude of being attentive to the apparent language, argument and thought in the text, but also to its "hesitations, paradoxes, aporiae, quotation marks, ellipses, footnotes, inconsistencies and confusions" (Critchley, 2005, p.556).

Re-examining the apparent paradox between the column and the shirttails therefore required a re-visit of the paratextual 'supplement' in Derridean terms, to allow for a different sort of unpacking of the column. The supplement, according to Derrida, is both a surplus to requirements and at the same time, something that makes up for a paucity, a lack, that must be filled to make up the whole. The supplement compensates and supplants what precedes it. In his attention to this 'maddening' quality of the supplement, Derrida argues that they may be misread as a postponing of apparently 'unimportant', less central material, when a closer observation can reveal their centrality to the text in question. The marginal supplement is often revealed as an essential, with a job of work of its own.The relegation of material to the extremities, the margins, is usually to underline and preserve the centrality, the purity, of the inside. They lend meaning and identity to the centre. Such supplements are therefore not just peripheral, but point to the central narrative's dependence on these margins: “...Less than nothing and yet, to judge by its effects, much more than nothing. The supplement is neither a presence nor an absence..." (Derrida, 1976, p.314)

Through their positioning, titling and content, the shirttails exhibit their paratextual 'quasidetachment' (Derrida, 1987, p. 59) from the main column. They seem at first glance, 'weird', that is, the strangeness relates to the juxtapositioning of elements that do not blend seamlessly 
(Fisher, 2016). The shirttails are predominantly preoccupied with the so-called 'WAGS' - wives and girlfriends - of football stars, their exotic-erotic affective labours, and improbable lifestyles as celebrities, compared to the serious job of the inside, the main column - that of exposing financial misdeeds, mismanagement and corruption of key (male) actors. For example, the edition of 23/4/2017 follows this pattern with what seem to be disjointed concerns between the main column and the shirttail:

\section{Also back in the news}

a) Trinidad's indicted Jack Warner-facing a federal fraud complaint in the US from Concacaf, who aim to recoup "not less than $\$ 20 \mathrm{~m}$ " from him and his former Trump Tower neighbour Chuck Blazer. Warner denies wrongdoing.

b) Former Costa Rica FA head Eduardo Li-banned last week for bribes and embezzling \$90k from the 2014 U17s Women's World Cup. Li told Fifa.com in 2014 what he'd gained from hosting the event: "Great pride and satisfaction."

c) Ghana FA head Kwesi Nyantakyi - taking time out to inaugurate "The Kwesi Nyantakyi Fan Club" and tipping himself for high office: "I deserve to be vicepresident at CAF. It's a path chosen for me by God."

And d) Brazil's FA - run by the indicted Marco Polo del Nero, successor to the indicted Ricardo Teixeira and the extradited Jose Maria Marin - announcing a $\$ 14.16 m$ profit at their general meeting: "During a crisis you grow, and find answers." All deny wrongdoing. Folha de S.Paulo: "At the end of the meeting, each FA executive left the building with a suitcase of gifts from sponsors."

The shirttail of this edition:

\section{And most generous}

Mexico: Celebrity witch Zulema, visiting struggling Cruz Azul to cleanse their aura with her "Ritual Satánico", featuring a cow's head, a pig's head, coconuts, sulphur and four candles. "No one paid me, I came for me. I just wanted to show peoplewitchcraft exists for good, not just bad".

At first glance, the contents of the main column and the shirttail seem to have little or no message/purpose in common. The column is preoccupied with issues of fraud, bribery, selfaggrandising officials, and a football association in the grip of indicted/extradited officials who continue to reap huge profits from a deeply corrupt culture. The shirttail in turn, details a phantasmic event involving Satanic rituals to boost a failing club's fortunes, referencing primitive, irrational and pre-modern realms. But the striking lesson from Derrida is that the supplement is really not quite so cleaved from the main (Derrida, 1981). The add-on, tacked at the end, can be revealed to be more than crucial to the centre, it may even cement the 'main' message. In this case, the shirttail can be read as signalling another flawed manifestation of the culture, relationships, structures and roles of people within the ambit of contemporary football, just as the main column does. The tailpieces may be distinctive in their politically incorrect tone on race, sexuality or gender matters but the female, primitive, wild and hypersexualised world they re-present cannot exist independently, outside of the world of male financial corruption that the main column critiques. Arguably, the tailpieces reinforce as well as mirror the gender, ethnic and financial hierarchies which make up the game of football. Indeed, the job of the main column in exposing the corruption and rot within football is accomplished by calling attention to the web of relations between the entities that meld together and present as global football: the European and Latin/African/Asian spheres; the male and female; corruption/sleaze and glamour/celebrity; hypermasculinity/hyperfemininity and sexualisation - which enmesh to become visible as the world of contemporary football. The 'gossipy' shirttails can be read as signalling both the differences and overlaps between these different elements. The invisibility of women's football in the 'main' column and the objectified Latina as erotic-exotic Other in the shirttails are part of the same problem, mirroring the unequal gender and ethnic dimensions of global football, that the main column works to expose. If the shirttails and the main column are indeed linked more closely than apparent, then it raises the question about the functioning of the 
shirttails: In what way are they 'much more than nothing', much more than morsels of lighthearted 'fun' peppering the pages? Are they perhaps more of a sting in the tail, exposing (without being explicit), the conditions within which not just football but sports media and the column itself operate? Such a reading of the relationships between the two parts of the text reveal how the issues presented in the shirttails loom over and haunt the more 'serious' issues which are given priority in the main column.

There are further insights about the role of the author, and the relationship with the reader, which a Derridean reading can offer. Derrida points out that an analysis of writing can reveal how texts often run away from their author's intentions, acquiring a power beyond intended meaning (Derrida, 1976). The multiple meanings, and complexities of the world which are inevitably contained within texts highlight how it may be a fool's errand to try to establish dominant authorial intentions. The polysemic nature of writing, where meaning disperses infinitely, like that drop of ink in water, and the resultant threat to the identification of the writer are notions that can alter a critical reader's relationship with the text. Textual interpretation of public media thus becomes more than learning to detect the true or hidden meaning of the text or the producers' intentions. Nor is it about how close the informed analyst can get to the 'actual' audience's readings. In Fursich's words, it is not even about exposing journalistic bias, instead, the goal is to explain "which cultural sensibilities prevail that allow for such a text at this specific point in time" $(2009, \mathrm{p} .247)$, and hence a focus on the "version of reality that becomes normalised" (2009, p.249).

To grasp how versions of reality become normalised inevitably requires a focus on how the text invites a reading public to take shape. And perhaps this is the most radical perspective offered by Derrida - his insistence that writing and its contradictions do not just lie waiting in texts to be analysed, but that they inhabit 'us', the readers too. There is no coherent, rational subject who can stand outside an objective text. Returning to the column with this radical notion, it appears that it is not so much the content of the main column that is 'liberal' but that it is constructed and located to invoke a particular position for the reading subject. As mentioned in the first reading of the column, it becomes intelligible only to a conscious, self-styled, liberal reader. Readers of snippets like the following in the main column are addressed with a confidence in their capacity to recognise and shun non-liberal, therefore repulsive or intolerable moments/events. The column becomes a 'liberal' one by evoking this liberal, reading subject.

\author{
Quote of the week \\ Brazil: Boa Esporte coach Julinho Camargo - "relaxed" about having early-release \\ murderer Bruno in his squad, several years after the keeper fed his girlfriend to dogs. \\ "It's not an issue, my focus is just on football. We all have a private life." (26/3/2017) \\ And most joined up \\ Fifa.com - offering new Obsese Person Tickets based on body mass index for "easy \\ access extra-width seats" at June's Confederations Cup in Russia. Tournament \\ sponsors: Budweiser and McDonalds. (5/3/17)
}

It is conceivable that the regular reader of the paper and this column would not be able to muster much sympathy for the footballer who murdered his girlfriend and fed her body to the dogs, the coach who claimed to be "relaxed" about his reintroduction into the squad, the producers of alcohol and high calorie food who sponsor extra-width seats for obese fans, or for the footballing institutions that see no conflict in earning revenues from such sponsorships. Thus the content of the column feeds the reading subject's identity and in concert with each other, the 'liberal' column becomes realised.

We can see that the critical gaze that was initially directed at the text, is then extended to the conditions of writing such texts, and finally turns around to come to rest on the critical readers/analysts themselves. With a Derridean perspective, the critical reader cannot position 
themselves as outside the text, looking in, but must become someone aware of their implication by/within the text and its conditions of possibility itself. Such an engagement with text progresses from the inside - it is always 'on guard against itself', paying attention to complicit practices. The critical reader is educated to stay with the radical discomfort caused by this engagement with his/her own positioning in this discursive space. Rather than muddy the clear politics of a normative reading, this kind of engagement with the text raises even more intimate, political questions such as, how we might know that we are on the 'right' side, and how our positioning in this discursive space indicates our own complicity. Readers of the column, football fans, are led to ask such uncomfortable questions of their participation in the sport and they inevitably open the door to questions about how it may be possible to resist injustices/inequalities and craft new worlds. This kind of reading is an intervention that cannot escape self examination and pays attention to the indeterminacies, silences, and paradoxes of texts in a manner that does not protect the reader from critique.

\section{Assembling critical readings}

In this paper, we have demonstrated the insights from three related but distinct approaches to critical reading as a way of gaining critical literacy amidst the ambiguity of the Said and Done column. The first reading displayed a sensibility of 'reading with the grain'. It focused on the main column and how it worked, through an analysis of its structural and rhetorical aspects layout, content, location, humour, repetition, satire - to produce fairly stable meaning. This also revealed the production of the reading subject as the liberal, cosmopolitan reader who was required to be informed of world and football affairs and actively engaged in reading between the lines.

The second reading was devoted to exclusively analysing the shirttails using a postcolonial feminist lens. This was in the tradition of 'reading against the grain', and aimed to expose the uncritical and illiberal nature of the shirttails. It was rooted in a normative stance, in a motive that seeks justice or truth. It was even a way of eliciting a 'correct consciousness' fuelled by critical righteousness (Lather, 2003; Leslie, 2000). Such an approach allows a critique of authorial (or publisher) ambitions, values and practices. In the process, the reader is positioned as a critical outsider, as someone outside the constituency for whom the text is intended. By mining the text for meaning, this approach exposes how techniques of Othering are deployed to produce the exotic-erotic Latin, staging this object for the readership of the metropolitan public. Postcolonial feminist frames help critique these values, point to the implications of such representations, and offer alternative ways of seeing and hearing the Othered. The politics of this kind of reading aims to move readers away from the Othering impulses of the text. The critique obliges the reader to be cognisant of the authorial powers to create and re-present, and encourages them to read against the sexist, racist or ethnicist sentiments in the shirttails.

The third reading, following a Derridean tradition worked from different impulses: it helped focus attention on the 'maddening' relationship between the tailpieces and the main column and raised questions about the links and perceived discrepancy between the territories covered by the supplement and the main. The idea of the supplement actively working to cement the message of the preceding material allows the reader to unravel the boundary between shirttails and the main column. It allows us to see afresh, features which cut across both sections - the sneering/mocking tone, the tight editing, the pithy details of dysfunction in both the financial and gendered realms of global football. A Derridean analysis questions the certainty and ease with which authors or readers can be defined. By requiring that the reader him/herself be subject to scrutiny, a more intimately radical subject position opens up. Rather than simply treat the text as the object of analysis, this approach also makes us confront how such texts 'make us up'. The conditions of possibility, of a normalisation of a version of reality, and how readers may be implicated in this reality, become explicit objects of focus. If normative critique focuses its energies on taking apart the text, the Derridean approach operates on the inside, taking apart the conditions that form a stable, if complacent, reading subject. 
This paper's argument is about the value of the assemblage/arrangement of these related yet distinctive approaches to text analysis. Where texts, such as the one considered in this paper, manifest themselves in a less defined, more enigmatic fashion, they reflect the flux and flow of discordant and discrepant ideas that are often packaged together for circulation. The different impulses that come together in the weave of texts can be usefully named and rendered visible through analytic assemblages. The term assemblage is used in the sense of a 'working arrangement' (Buchanan 2015), a conscious invitation to different theoretical-political stances to analyse the text. It is the intersection of perspectives makes the arrangement/assemblage work as analysis.

There are conditions and caveats that come with such arrangements - they must be understood as contingent and unpredictable. They are different from practices of 'that seek to accommodate, relativise, assimilate or resolve differences between perspectives. The practice of assembling different critical perspectives can be an uncomfortable one that requires the critical reader to hold different perspectives (for example, on authorship/production, readership/consumption, and relations between them), without seeking a resolution. The critical righteousness of normative critique is both given its place - training its focus on behalf of the (literally) marginalised - as well as extended, by the critical considerations about the reader her/himself caught up in the circuits of political economy that sport media themselves are part of. Critical media education today demands that such distinct sensibilities are set to work in concert with each other without privileging one over the other. While each could, in theory, be used separately, conducting three sets of analyses, iteratively, allows for a deeper critical literacy.

This argument of the paper - that the practice of assembling different critical perspectives is a necessary approach to make better sense of polysemous, ambiguous media texts - offers both a solution and a challenge to the pedagogical task of facilitating critical literacies. The contemporary mediascape demands that pedagogues expand their critical political, methodological or theoretical inclinations to explicate how unique insights from a range of perspectives help better comprehend, and respond to this complexity. Critical media readership can then become a composite practice, one that sifts through and patches together approaches and orientations that move readers in the many directions that are needed to make sense of words and worlds. 


\section{References:}

Adams, A. (2011). “"Josh wears pink cleats": Inclusive masculinity on the soccer field.' Journal of Homosexuality, 58(5), 579-596.

Anderson, E. (2010) "Inclusive masculinities of university soccer players in the American Midwest." Gender and Education, 23(6), 729-744.

Arrizón, A. (2008) 'Latina subjectivity, sexuality and sensuality.' Women and Performance: A Journal of Feminist Theory, 18(3),189-198.

Benwell, B. (2007) 'New Sexism?' Journalism Studies, 8(4), 539-549.

Bhabha, H. (1994). The location of culture. New York: Routledge.

Boyle, R. \& Haynes, R. (2009). Power Play: Sport, the Media and Popular Culture, Edinburgh University Press.

Brookey, R., and Gray, J. (2017) "Not merely para": continuing steps in paratextual research. Critical Studies in Media Communication, 34(2), 101-110.

Buchanan, I. (2015) Assemblage Theory and its Discontents. Deleuze Studies, 9(3), 382-392.

Colletta, L. (2009). Political Satire and Postmodern Irony in the Age of Stephen Colbert and Jon Stewart. The Journal of Popular Culture, 42(5),856-874.

Cooper, R. (1989). Modernism, Postmodernism and Organizational analysis 3: The Contribution of Jacques Derrida. Organization Studies, 10(4), 479-502.

Cortes, OC. (2003). Semiotic alteration in translation: Othering, stereotyping and hybridization in contemporary translations from Arabic into Spanish and Catalan. Linguistica Antverpiensia, 2, 145-159.

Critchley, S. (2005) Derrida: The Reader. Cardozo Law Review, 27(2), 553-565.

Derrida, J. (1976). Of Grammatology. (G.C.Spivak, Trans.). Baltimore: John Hopkins University Press.

Derrida, J. (1987). The Truth in Painting. (G.Bennington \& I.McLeod, Trans.). Chicago \& London: University of Chicago Press.

Derrida, J. (1981). Dissemination. (B.Johnson, Trans.). Chicago: University of Chicago Press.

Fisher, M. (2016). The Weird and the Eerie. London: Repeater Books.

Flax, J., (1990). Thinking Fragments: Psychoanalysis, Feminism and Postmodernism in the Contemporary West, Berkley, California: University of California Press.

Fürsich, E. (2009). In Defense of Textual Analysis: Restoring a challenged method for journalism and media studies. Journalism Studies, 10 (2), 238-252.

Gentzkow, M., Shapiro, J., \& Sinkinson, M., Competition and Ideological Diversity: Historical Evidence from US Newspapers. American Economic Review 2014, 104(10), 3073-3114.

Gibbs, R., Kushner, J., \& Mills, W. (1991). Authorial intentions and metaphor comprehension. Journal of Psycholinguistic Research, 20, 11-30.

Irigaray, L. (1985). This sex which is not one. (C.Porter with C.Burke, Trans.). NY: Cornell University Press.

Kreuze, R., \& Roberts, R. (1993). On Satire and Parody: The Importance of Being Ironic. Metaphor and Symbolic Activity 8(2), 97-109.

LaMarre, H., Landreville, K., \& Bearn, M. (2009). The Irony of Satire: Political Ideology and the Motivation to See What You Want to See in The Colbert Report. International Journal of Press/Politics, 14(2), 212-231.

Lather, P. (2003). 'Applied Derrida: (Mis)reading the work of mourning in educational research'. Education, Philosophy and Theory 35(3), 257-270.

Leach, J. (2004). British Film. Cambridge: Cambridge University Press.

Leslie, E. (2000). Walter Benjamin: Overpowering conformism. London: Pluto.

Loomba, A., (1998). Colonialism/Postcolonialism. London \& New York: Routledge.

Luke, A., \& Woods, A. (2009). Critical Literacies in Schools: A Primer. Voices from the Middle, 17(2), 9-18.

Luke, A. (2012). Critical Literacy: Foundational Notes. Theory Into Practice, 51(1), 4-11.

Magrath, R. (2017). Inclusive masculinities in contemporary football: Men in the beautiful game. Oxon, NY: Routledge.

McArthur, T. (1986). Worlds of reference: lexicography, learning and language from the clay tablet to the computer. Cambridge: Cambridge University Press 
McClintock, A. (1995). Imperial Leather: Race, Gender and Sexuality in the Colonial Contest. London: Routledge.

Mendible, M. (Ed.). (2007). From Bananas to Buttocks: The Latina Body in Popular Film and Culture. Austin: University of Texas Press.

Mey, J. (1986). Whose Language: A Study in Linguistic Pragmatics. Amsterdam: John Benjamin.

Mills, J. \& Sen, S. (2004). Confronting the Body: The Politics of Physicality in Colonial and Post-colonial India. London: Anthem Press.

Moore-Gilbert, B., (1997). Postcolonial Theory: Contexts, Practices, Policies London: Arnold.

New London Group. (1996). A pedagogy of multiliteracies: Designing social futures. Harvard Educational Review, 66, 60-92.

Prasad, A. (Ed.). (2003), Postcolonial Theory and Organizational Analysis: A Critical Engagement, New York: Palgrave Macmillan.

Prasad, A., (1997). The Colonizing Consciousness and Representaitons of the OtherL A Postcolonial Critique of the Discourse of Oil. In P. Prasad, A.J.Mills, M.E.Imes, \& A. Prasad, (Eds.). Managing the Organizational Melting Pot: Dilemmas of Workplace Diversity (pp. 285-311). 1000Oaks, London, New Delhi: Sage.

Rivers-Moore, M. (2013). Affective sex: Beauty, race and nation in the sex industry. Feminist Theory, 14 (2),153-169.

Ross, K. and Carter, C. (2011). Women and news: A long winding road. Media, Culture and Society, 33, (8), 1148-1165.

Savigliano, M. (1995). Tango and the Political Economy of Passion. Oxford: Westview.

Streicher, R. (1967). On a Theory of Political Caricature, Comparative Studies in Society and History, 9, (4),427-445.

Weiguo, Q. (2013). Dehistoricized cultural identity and cultural othering. Language and Intercultural Communication, 13(2),148-164.

Zwann, R. (1991). Some parameters of literary and news comprehension: Effects of discoursetype perspective on reading rate and surface structure representation. Poetics 20, 139-156.

Figure 1. Page shot of column from March 12, 2017. 